\title{
Trigeminal Neuralgia: A Rare Cause of Facial Pain in a Child
}

\author{
Arzu Ekici ${ }^{\mathrm{a}, \mathrm{c}}$, Ayten Yakut ${ }^{\mathrm{a}}$, Armagan Incesulu ${ }^{\mathrm{b}}$, Sevgi Yimenicioglu ${ }^{\mathrm{a}}$, \\ Ozan Kocak ${ }^{\mathrm{a}}$, Kursat Bora Carman ${ }^{\mathrm{a}}$
}

\begin{abstract}
Trigeminal neuralgia is a rare form of facial pain in children. It may be primary or secondary. We report a 10 -year-old girl with idiopathic trigeminal neuralgia who was treated with carbamazepine successfully.
\end{abstract}

Keywords: Facial pain; Trigeminal neuralgia; Idiopathic; Carbamazepine; Child

\section{Introduction}

Trigeminal neuralgia (TGN) is a form of facial pain which is uncommon in children. Trigeminal neuralgia is defined as a sudden, usually unilateral, severe, brief, stabbing, recurrent pain in the distribution of one or more branches of the fifth cranial nerve. It may be primary or secondary [1]. Anti-epileptic drugs have been widely used in the treatment of pain since 1960s [2]. We report a 10-year-old girl with idiopathic TGN who was treated with carbamazepine successfully.

\section{Case Report}

A 10-year-old girl was admitted to our department with the complaint of pain in the right cheek and tinnitus in the same ear for 6 weeks. The pain was sudden and electric shocklike.

Manuscript accepted for publication October 11, 2013

${ }^{a}$ Department of Pediatric Neurology, Osmangazi University Medicine Faculty, Eskisehir, Turkey

${ }^{\mathrm{b}}$ Department of Otolaryngology, Osmangazi University Medicine Faculty, Eskisehir, Turkey

${ }^{\mathrm{c}}$ Corresponding author: Arzu Ekici, Akarbasi Mah. Sehit Zeynel Tokoz Sok. Oncag Park Sitesi C Blok Daire: 6, Eskisehir, Turkey.

Email: drarzuekici@gmail.com

doi: http://dx.doi.org/10.4021/ijcp113w
It lasted for a few seconds and repeated one or two times in a day. She interrupted activity during the pain. The pain was not aggravated on brushing the teeth, touch or chewing. She had no tearing, facial numbness or dizziness. She used several antibiotics and analgesics, but no benefit was provided. She has a history of adenoidectomy 2 years ago.

Neurological and otological examinations were normal. She does not have any tooth problem. Bilateral hearing tests and electroencephalography were normal. Magnetic resonance imaging (MRI) and MR angiography revealed no pathological findings. Carbamazepine (CBZ) $10 \mathrm{mg} / \mathrm{kg} /$ day was administered. She have had only two attacks within 2 months and CBZ dose increased $(15 \mathrm{mg} / \mathrm{kg} /$ day $)$. After the increasement of $\mathrm{CBZ}$, she became pain free.

\section{Discussion}

The incidence of TGN is estimated at 12.6 per 100,000 person-years, with the mean age at diagnosis of 51.5 years and women are more often affected than men [3]. Rarely, TGN presents during childhood and only $1.5 \%$ of cases occur in pediatric cases [4]. The diagnosis of TGN is based on clinical findings and there have not been any case controlled studies to validate diagnostic methods [5]. The International Headache Society defined TGN's criteria as paroxysmal attacks of pain lasting from a fraction of a second to $2 \mathrm{~min}$. Pain is intense, sharp, superficial or stabbing and precipitated from trigger areas or by trigger factors. Attacks are stereotyped in the individual patient. There is no clinically evident neurological deficit and it does not attribute to another disorder [6]. The onset and termination of TGN episodes are usually paroxysmal and patients are generally free of pain between attacks. The pain is unilateral in most patients [1].

TGN is genarally idiopathic and the other causes must be excluded for idiopathic TGN. Vascular compression is thought to be the main cause in both adults and children [7]. Symptomatic TGN can be due to tumors, vascular malformations, and multiple sclerosis $[7,8]$. The most important test is brain MRI for revealing the etiology of the pain and most studies support the combined use of MRI and MR angiography in the evaluation of TGN [9-11]. 
The initial treatment of patients with TGN is medical therapies such as carbamazepin, oxcarbazepine, phenytoin, and gabapentin. The surgical treatments consisting of microvascular decompression, percutaneous rhizotomies, and stereotactic radiosurgery should be considered when medical therapies fail to control pain. However, surgical results in children were not satisfactory as adults [4]. Lopes et al [12] reported two children with idiopathic TGN who responded to medical treatment. But multiple drugs like gabapentin, oxcarbazepine, amitrptyline, chlorpromazine, and carbamazepine were given. Silva et al [13] reported a patient whose symptoms completely relieved only one week after initiation of carbamazepine. In our patient, we did not find any etiologic cause and evaluated idiopathic TGN. She had a good response to carbamazepine. Unfortunately before carbamazepine she had used several antibiotics and analgesics without any success.

In summary, TGN is a rare disorder in children. We want to emphasize that children with facial pain should be considered of TGN. Carbamazepin is the most frequently used drug and our patient had a good response to carbamazepine.

\section{References}

1. Montgomery MT. Extraoral facial pain. Emerg Med Clin North Am. 2000;18(3):577-600, vii-viii.

2. McQuay H, Carroll D, Jadad AR, Wiffen P, Moore A. Anticonvulsant drugs for management of pain: a systematic review. BMJ. 1995;311(7012):1047-1052.

3. Koopman JS, Dieleman JP, Huygen FJ, de Mos M, Martin CG, Sturkenboom MC. Incidence of facial pain in the general population. Pain. 2009;147(1-3):122-127.
4. Resnick DK, Levy EI, Jannetta PJ. Microvascular decompression for pediatric onset trigeminal neuralgia. Neurosurgery. 1998;43(4):804-807; discussion 807-808.

5. Zakrzewska JM. Diagnosis and differential diagnosis of trigeminal neuralgia. Clin J Pain. 2002;18(1):14-21.

6. International Headache Society Classification Subcommittee. International Classification of Headache Disorders. Cephalalgia. 2004;24(Suppl 1):1-160.

7. Childs AM, Meaney JF, Ferrie CD, Holland PC. Neurovascular compression of the trigeminal and glossopharyngeal nerve: three case reports. Arch Dis Child. 2000;82(4):311-315.

8. Hooge JP, Redekop WK. Trigeminal neuralgia in multiple sclerosis. Neurology. 1995;45(7):1294-1296.

9. Cohen J. Role of the neurologist in the evaluation and treatment of patients with trigeminal neuralgia. Neurosurg Focus. 2005;18(5):E2.

10. Fukuda H, Ishikawa M, Okumura R. Demonstration of neurovascular compression in trigeminal neuralgia and hemifacial spasm with magnetic resonance imaging: comparison with surgical findings in 60 consecutive cases. Surg Neurol. 2003;59(2):93-99; discussion 99-100.

11. Patel NK, Aquilina K, Clarke Y, Renowden SA, Coakham HB. How accurate is magnetic resonance angiography in predicting neurovascular compression in patients with trigeminal neuralgia? A prospective, single-blinded comparative study. Br J Neurosurg. 2003;17(1):60-64.

12. Lopes PG, Castro ES, Jr., Lopes LH. Trigeminal neuralgia in children: two case reports. Pediatr Neurol. 2002;26(4):309-310.

13. Silva LA, Siqueira SR, Siqueira JT, Teixeira MJ. Facial somatosensorial evaluation in idiopathic trigeminal neuralgia. Arq Neuropsiquiatr. 2012;70(1):73-74. 